\title{
Soybean Root Suberin and Partial Resistance to Root Rot Caused by Phytophthora sojae
}

\author{
Kosala Ranathunge, Raymond H. Thomas, Xingxiao Fang, Carol A. Peterson, Mark Gijzen, and Mark A. Bernards
}

First, third, and fourth authors: Department of Biology, University of Waterloo, Waterloo, ON, Canada, N2L 3G1; second and sixth authors: Environmental Stress Biology Group, Department of Biology, University of Western Ontario, London, ON, Canada, N6A 5B7; and fifth author: Agriculture and Agri-Food Canada, London, ON, Canada, N5V 4T3.

Current address of first author: Department of Ecophysiology, IZMB, University of Bonn, Kirschallee 1, D-53115, Bonn, Germany.

Accepted for publication 29 May 2008.

\begin{abstract}
Ranathunge, K., Thomas, R. H., Fang, X., Peterson, C. A., Gijzen, M., and Bernards, M. A. 2008. Soybean root suberin and partial resistance to root rot caused by Phytophthora sojae. Phytopathology 98:1179-1189.

Phytophthora sojae is the causal agent of root and stem rot of soybean (Glycine max). Various cultivars with partial resistance to the pathogen have been developed to mitigate this damage. Herein, two contrasting genotypes, the cultivar Conrad (with strong partial resistance) and the line OX760-6 (with weak partial resistance), were compared regarding their amounts of preformed and induced suberin components, and to early

plants more time to establish their chemical defenses. Subsequent growth of hyphae through the endodermis was also delayed in Conrad. This cultivar had more preformed aliphatic suberin than the line OX760-6 and was induced to form more aliphatic suberin several days prior to that of OX760-6. However, the induced suberin was formed subsequent to the initial infection process. Eventually, the amount of induced suberin (measured 8 days postinoculation) was the same in both genotypes. Preformed root epidermal suberin provides a target for selection and development of new soybean cultivars with higher levels of expression of partial resistance to $P$. sojae.
\end{abstract} events during the $P$. sojae infection process. To colonize the root, hyphae grew through the suberized middle lamellae between epidermal cells. This took 2 to $3 \mathrm{~h}$ longer in Conrad than in OX760-6, giving Conrad
Additional keywords: oomycete hyphal staining, preformed defenses, root epidermis.
Each year in agriculture, millions of dollars are lost due to soybean (Glycine max [L.] Merr.) root rot caused by the plant-pathogenic oomycete Phytophthora sojae (Kaufmann and Gerdemann) $(6,47)$. To counteract such losses, resistant cultivars of soybean have been developed. There are two types of resistance to $P$. sojae in soybean: race-specific resistance and partial resistance (also called quantitative resistance, tolerance, or field resistance). The appearance of new virulent pathogen races in response to continued use of race-specific resistant cultivars has led to documented failures in disease control $(17,41)$. Once incorporated into soybean cultivars, Rps (resistance) genes have an effective life of only 8 to 15 years before new virulent races of the pathogen evolve $(3,6,33)$. As a result, current disease management recommendations emphasize the use of partial resistance as a more durable strategy to control $P$. sojae $(3,4,6,8,44)$. Partial resistance in soybean restricts pathogen colonization of plant tissue and is an inherited, quantitative trait considered to be effective against all races of $P$. sojae $(3,40,48)$. As the complexity of the virulence pathotypes of $P$. sojae continues to increase and the number of designated races increases in areas of soybean production, identifying additional sources of partial resistance and incorporation of this resistance into commercial cultivars will be essential for effective disease management.

The sequence of events whereby $P$. sojae invades roots is well known and is similar to other oomycete infection processes $(7,10$, 11,18,49). This soilborne pathogen produces motile zoospores that spread in water and are attracted to soybean root exudates $(30,31,50)$. Once on the root surface, the zoospores adhere to the

Corresponding author: C. A. Peterson; E-mail address: cpeterson@uwaterloo.ca

doi:10.1094/PHYTO-98-11-1179

(C) 2008 The American Phytopathological Society root, encyst, and then begin to germinate. Germ tubes penetrate into the root by growing directly through the middle lamellae of the epidermal cells $(7,42,43)$. Continued growth occurs in cortical air spaces and through the middle lamellae of abutting cells. Hyphae may grow through the endodermis (especially in susceptible cultivars) breaching the outer and inner tangential walls (and cell protoplast) and advance to colonize the xylem (7).

Our previous work indicated a strong correlation between the extent of preformed suberin, especially its poly(aliphatic) constituent, in soybean roots and partial resistance to P. sojae (46). In other pathosystems, a similar role for preformed suberin has also been established. For example, in potatoes, suberin is known to (i) constitute a barrier to diffusion of pathogen enzymes or toxins into living tissues, (ii) provide a structural impediment to pathogen ingress, and (iii) be toxic to microbes due to the high proportion of phenolic materials incorporated into the polymer $(20,25)$. This is further evident in recent data demonstrating that a compromised potato tuber suberin layer results in a greater susceptibility to postharvest tuber rot and the development of "pink eye" (26). Similarly, the role of induced suberization in the resistance response to Verticillium infection has been demonstrated in tomato (38) and more recently potato (24).

In soybean roots, preformed suberin occurs in several locations $(9,46)$. First, diffuse suberin is interspersed among other wall components in cells of the epidermis and adjacent cortex. Second, suberin, as a constituent of Casparian bands, occurs in the anticlinal walls of the endodermis. Third, as the root ages, suberin lamellae appear in some cells of the endodermis. Our previous work indicated that roots of a soybean cultivar (Conrad) with strong partial resistance to $P$. sojae had substantially more preformed suberin in its roots than a line (OX760-6) with weak partial resistance, and also that there was a strong negative correlation between the amount of preformed suberin, especially its 
poly(aliphatic) constituent, and mortality in $P$. sojae-infested fields among 32 recombinant inbred lines derived from these two parents (46).

To determine whether this preformed suberin in the epidermal walls of soybean roots plays a direct role in retarding $P$. sojae infection, a time sequence of the pathogen ingress was compared in Conrad and OX760-6. In addition, the potential role of induced suberin in the partial resistance to this pathogen was determined by characterizing the chemistry and location of suberin developed postinfection, and by following the time sequence of its development.

\section{MATERIALS AND METHODS}

Plant materials. Seeds of soybean (Glycine max) cv. Conrad and line OX760-6 were obtained from field-grown plants at Agriculture and Agri-Food Canada (London, Ontario, Canada). The two genotypes have different levels of partial resistance to $P$. sojae (19). Conrad has strong partial resistance, whereas OX7606 has weak partial resistance to this pathogenic oomycete (46). Both are standards commonly used in greenhouse and field assays to measure partial resistance to $P$. sojae.

Histochemical detection of preformed suberin in young zones of soybean roots. Seeds were surface sterilized with $0.5 \%$ sodium hypochlorite (commercial Javex bleach; Clorox Co. of Canada, Brampton, Ontario) for $5 \mathrm{~min}$, and then rinsed several times with sterile distilled water. These seeds were soaked in distilled water for $12 \mathrm{~h}$ and planted in 195-mm-diameter plastic pots (195 mm depth) in vermiculite (\#2A, Therm-O-Rock East Inc., New Eagle, Pennsylvania) saturated with distilled water. Plants were grown in a chamber with alternating light, approximately $16 \mathrm{~h}$ at $25^{\circ} \mathrm{C}$, and dark, $8 \mathrm{~h}$ at $20^{\circ} \mathrm{C}$ under $60 \%$ relative humidity. Plants were watered daily with sterilized tap water.

Seedlings grown for 7 days were uprooted and washed to remove vermiculite from their roots. Freehand cross sections were taken from five primary roots at distances of 2,10 , and $50 \mathrm{~mm}$ from their tips. All preparations were viewed with a Zeiss Axiophot epifluorescence microscope (Carl Zeiss Canada, Don Mills, Ontario, Canada). Suberin was identified using the combined results of the following techniques: autofluorescence when excited with blue light (filter set: exciter BP 450-490 nm, dichroitic mirror FT $510 \mathrm{~nm}$, and barrier LP $520 \mathrm{~nm}$; 34), Fluorol yellow 088 (2), and acid digestion (15). Phenolic substances are recognized by their autofluorescence, aliphatics by their yellow fluorescence after Fluorol yellow 088 staining, and the suberin polymer by its insolubility in concentrated sulfuric acid. For the latter test, sections were placed in the acid on a slide and incubated for $48 \mathrm{~h}$ prior to observation.

Inoculation of plant roots with the pathogen. $P$. sojae race 2 (strain P6497) was maintained at Agriculture and Agri-Food Canada, London. The oomycete was cultured under aseptic conditions on $26 \% \mathrm{~V} 8$-juice agar $\left(8.4 \mathrm{~g}\right.$ of agar, $1.6 \mathrm{~g}$ of $\mathrm{CaCO}_{3}, 156 \mathrm{ml}$ of V8 juice [Campbell Soup Company, Toronto, Ontario, Canada], and $440 \mathrm{ml}$ of $\mathrm{H}_{2} \mathrm{O}$ ) for 8 days.

To follow the sequential events in the infection process in roots of Conrad and OX760-6, zoospores were produced by flooding 8-day-old cultures of $P$. sojae with sterile distilled water and incubating them at $22^{\circ} \mathrm{C}$ overnight. The water was replaced with fresh distilled water every half hour for at least $5 \mathrm{~h}$. When zoospores could be detected microscopically, the water was decanted and the zoospore concentration was determined by adding a drop of $0.1 \%$, wt/vol, aniline blue in lactophenol (1:1:1 85\% lactic acid, phenol, and water; 9) to $1 \mathrm{ml}$ of the zoospore suspension; a $10-\mu l$ aliquot of this was loaded with a pipette into a hemacytometer. The zoospore concentration was calculated and adjusted to $1 \times 10^{4}$ zoospores $\mathrm{ml}^{-1}$ with sterile deionized water. Meanwhile, soybean plants grown for 7 days as described above were carefully uprooted from pots, and vermiculite was removed with- out damaging the roots. They were directly incubated in the zoospore suspension at room temperature $\left(22^{\circ} \mathrm{C}\right)$ for the desired inoculation times.

For chemical analyses and histochemical detection of induced suberin in roots of Conrad and OX760-6 plants, seeds were soaked overnight prior to planting in wax-paper cups $(8.5 \mathrm{~cm}$ top diameter $\times 15 \mathrm{~cm}$ deep; Merchants Paper Company, Windsor, Ontario, Canada) with drainage holes cut in the bottom. P. sojae P6497 was grown as described above for 8 days to produce culture inoculums. Agar disks containing cultures were cut and fitted into the bottoms of the cups and overlaid with medium-grade vermiculite. One set of plants from each line was inoculated with race 2 , and the other set mock-inoculated as the control, i.e., sterile V8-juice agar disks were substituted for $P$. sojae cultures. Plants were grown in a greenhouse and maintained at $25^{\circ} \mathrm{C}$ and $24 \mathrm{~h}$ continuous light. Four days after germination, plants were watered daily with 1/4-strength Knop's solution (23). The entire root system was harvested 14 days after germination (8 days after inoculation), the necrotic regions were excised, and the remaining root tissue was analyzed for wax composition, aliphatic and phenolic suberin as previously described $(46,56)$.

Comparison of the infection process in Conrad and OX7606. According to an initial time course study, a $2 \mathrm{~h}$ incubation was sufficient for zoospores to adhere and encyst on the root surface. Roots of intact soybean seedlings were immersed in the zoospore suspension for $7 \mathrm{~h}$ at room temperature. The infected roots were rinsed with sterilized distilled water several times and segmented into $5 \mathrm{~mm}$ pieces. Segments were cleared in $85 \%$ lactic acid at $98^{\circ} \mathrm{C}$ for $1 \mathrm{~h}$. The delicate cleared segments were transferred to test tubes by means of a loop and rinsed with deionized water $(3 \times$ $20 \mathrm{~min}$ ). Cleared segments were mounted on slides and observed under white light with a compound microscope (Zeiss Axiophot). The numbers of adhering or encysted zoospores on the root surfaces were counted at four different zones from the root tip $(0$ to 5,10 to 15,45 to 50 , and 95 to $100 \mathrm{~mm}$ ) for six roots of each genotype.

To determine the time course of zoospore germination on the root surface, primary roots of both genotypes were incubated in the zoospore suspension for 1, 2, 3, 4, and $5 \mathrm{~h}$. Inoculated roots were cleared and rinsed as described above. The delicate cleared roots were scooped out of the water with a loop and blotted dry with an absorbent paper. One hundred zoospores were randomly counted within a $0.5 \times 2 \mathrm{~mm}$ rectangle adjacent to the root cap with a compound white light microscope; the number of zoospores adhering to or encysted on the root was recorded for five roots of each genotype.

$P$. sojae germ tube elongation on the root surface was studied by incubating primary roots of both genotypes in the zoospore suspension for $1,2,5$, and $10 \mathrm{~h}$. The younger root parts $(0$ to $5 \mathrm{~mm}$ from the tip) were excised and dehydrated through a graded series of acetone solutions (20\% per step) to absolute. Critical point drying was performed with liquid $\mathrm{CO}_{2}$ on a Denton Critical Point Drying Apparatus (DCP-1, Denton Vacuum Co., Cherry Hill, NJ). The specimens were mounted on stubs, coated with a layer of gold in a Polaron E5000C PS3 Sputter Coater (Polaron Equipment Co., Watford, England), and then viewed with a Hitachi S-570 scanning electron microscope. Photographs were taken on $35 \mathrm{~mm}$ ILFORD PanF Plus film, ISO 50.

To follow the time course of $P$. sojae hyphal penetration into roots and observe subsequent hyphal growth, it was necessary to stain the hyphae within the roots. Many unsuccessful attempts were made using a variety of methods: chlorazol black E, aniline blue (for callose), aniline blue and trypan blue together, and cellufluor (for cellulose). The following procedure of Welc was the only one that provided good contrast between the hyphae and the plant cells (54 [modified from 21]). Primary roots were immersed directly into a zoospore suspension at room temperature for $2,5,8$, and $24 \mathrm{~h}$ and growth of the hyphae into the roots was 
studied over time for both genotypes. Freehand cross sections were cut between 2 and $10 \mathrm{~mm}$ from the tips of infected roots, put into test tubes, and cleared with $10 \% \mathrm{KOH}$ at $90^{\circ} \mathrm{C}$ for $30 \mathrm{~min}$. After removal from the $\mathrm{KOH}$, the cleared sections were rinsed with tap water for $20 \mathrm{~min}$ and soaked in a bleaching solution of a mixture of $10 \% \mathrm{H}_{2} \mathrm{O}_{2}$ and $25 \% \mathrm{NH}_{4} \mathrm{OH}$ for $30 \mathrm{~min}$, followed by staining with $2 \%$ aqueous trypan blue (C.I. 23850, Sigma Chemical Co., St. Louis, MO) at $90^{\circ} \mathrm{C}$ for $3 \mathrm{~min}$. The stained samples were destained in lacto-glycerol (lactic acid/glycerol/ distilled water, 1:1:1) for 4 to $5 \mathrm{~min}$, transferred to slides, mounted in $75 \%$ glycerol, and viewed with a white light microscope (as above). Photos were taken with a digital camera system (QImaging, Retiga 2000R, Fast 1394, Cooled Mono, 12-bit, Quorum Technologies Inc., Guelph, Ontario, Canada).

Numbers of hyphal penetrations through the epidermis or endodermis were counted in sections from both genotypes with different infection times. The percentages of hyphal penetrations across either the epidermis or endodermis at specific times were calculated by dividing the number of sections with hyphae that had penetrated the relevant layer by the total number of sections in which hyphae were observed at some position in the root for each infection time. Numbers of replicates $(N)$ ranged from three to nine.

Time course of suberin induction in roots of Conrad and OX760-6. A time course study was designed to determine if and at what rate suberin was induced by inoculation with $P$. sojae in two soybean genotypes differing in partial resistance to this pathogen. For each time point, three cups were inoculated with the pathogen and another three cups were mock-inoculated as a control as described above. This design was repeated for both soybean genotypes, and the whole experiment was repeated twice. Entire root systems were harvested every 2 days up to 8 days after inoculation (assumed to take place 6 days postgermination) and then after an additional 7 days.

Quantitative suberin analysis. The necrotic regions were excised from the harvested roots, and the remaining tissue was extracted with $\mathrm{CHCl}_{3}-\mathrm{MeOH}$; this yields an extractive-free cell wall residue for analysis. The organic-soluble compounds in the $\mathrm{CHCl}_{3}-\mathrm{MeOH}$ extract provide a measure of the wax associated with suberin.

Since suberin is an intractable cell wall polymer comprised of two chemically distinct domains, a quantitative measure can only be obtained using specific depolymerization methods for each. For the poly(phenolic) domain, microscale alkaline nitrobenzene oxidation (NBO; 28), as modified by Thomas et al. (46), was used. This yields an estimate of the phenolic suberin in the tissue. For the poly(aliphatic) domain, $\mathrm{BF}_{3} / \mathrm{MeOH}$-catalyzed transestrification (36 [as modified by 54]) was used. This yields an estimate of the aliphatic suberin in the tissue, as well as a measure of the amount of phenolics esterified within the poly(aliphatic) domain.

Histochemical detection of induced suberin. Soybean plants were inoculated with $P$. sojae hyphae in agar as described earlier. Roots of both infected and control plants were harvested 14 days after germination and washed to remove vermiculite from the roots. Freehand cross sections of primary roots were made above the most apical point of root decay and suberin was detected as described above, except that phenolics were also detected with the Hoepfner-Vorsatz test $(22,37)$ where a yellowish orange color is seen with white light. All photographs were of sections taken $1 \mathrm{~cm}$ from the necrotic tip of infected roots and a comparable region of control roots.

Statistics. Each experiment was repeated at least twice. For the chemical analysis, three replicates were analyzed for each experiment. General analysis of variance (ANOVA) was used to determine the effects of treatments on suberization. Where treatment effects were significant, Fisher's least significant difference (LSD) was used to compare the means at $P=0.05$. Comparison of stages of infection process between Conrad and OX760-6 was done using ANOVA, and LSD was used to compare the means at $P=$
0.05 . The data were analyzed using the Statistix software package (version 2.0, Analytical software, Tallahassee, FL). Statements in the text indicating differences are based on the detection of a significant difference at the $5 \%$ level.

\section{RESULTS}

Early events in $P$. sojae infection of soybean roots. The average length of 7-day-old primary roots of Conrad and OX7606 plants was $100 \mathrm{~mm}$. The pots used (with a depth of $195 \mathrm{~mm}$ ) allowed the root tips to grow down freely so that early events in root maturation occurred over the longest possible distance. The epidermis was first exposed $2 \mathrm{~mm}$ from the root tip, the younger regions being covered by the root cap. At this distance from the root tip, phenolics were detected by a faint yellow autofluorescence in all epidermal cell walls, including the radial walls of both genotypes (Fig. 1A and D). The intensity of the fluorescence increased along the root toward its base, indicating that the quantity of phenolics increased in this direction (Fig. 1B, C, E, and $\mathrm{F}$ ). The fluoresced color of the epidermal walls also changed from yellowish green to yellowish orange with root age (Fig. 1A to F). At $50 \mathrm{~mm}$ from the root tip, the outer tangential epidermal walls were thicker than the others in both genotypes (Fig. 1C and F), and the outer tangential and some radial walls of adjacent cortical cells also showed faint autofluorescence.

Aliphatics were indicated by yellowish green fluorescence after staining sections with the lipophilic fluorochrome Fluorol yellow 088. This fluorescence was apparent $2 \mathrm{~mm}$ from the root tips in all walls of the epidermis of both Conrad (Fig. 1G) and OX760-6 (Fig. 1J). The brightness of fluorescence increased along the root toward the base of Conrad (Fig. 1H and I) and OX760-6 (Fig. 1K and L), and the fluorescence in the epidermal walls changed from yellowish green to yellowish orange with root age, especially in Conrad (Fig. 1G to I). In both genotypes, the outer tangential and radial walls of adjacent cortical cells contained aliphatics $50 \mathrm{~mm}$ from the root tip but more appeared to be present in Conrad than that of OX760-6. In both, but consistently in Conrad, intercellular air spaces between the epidermis and adjacent cortical cells were occluded by aliphatics.

Acid digestion, which removes all carbohydrate and nonpolymerized phenolics and aliphatics from cells, yielded the same results for Conrad and OX760-6; results are only shown for Conrad (Fig. $1 \mathrm{M}$ to $\mathrm{O}$ ). Considering only the epidermis and adjacent cortex, in sections taken $2 \mathrm{~mm}$ from the root tip, only the outer tangential and radial walls of the epidermis resisted acid digestion (Fig. 1M). In sections farther from the tip, e.g., 10 (Fig. $1 \mathrm{~N}$ ) and $50 \mathrm{~mm}$ (Fig. 1O), the inner tangential walls of the epidermis and some outer tangential and radial walls of the adjacent cortical layer also remained after acid digestion. These walls were attached to each other, indicating that the middle lamellae between the cells were also modified.

Zoospores primarily accumulated on the surfaces of young parts of soybean roots with the largest number being observed 0 to $15 \mathrm{~mm}$ from the root tip (Fig. 2A). At $100 \mathrm{~mm}$ from the root tip, almost no zoospores were present. There was no apparent difference in the accumulation and adhesion of zoospores on the roots of Conrad and OX760-6. Similarly, the germination of zoospores on the root surface initiated $1 \mathrm{~h}$ after inoculation and was complete in both Conrad and OX760-6 by $4 \mathrm{~h}$ (Fig. 2B). There was no significant difference in the percentage of germinated zoospores on the root surface of Conrad compared with that of OX760-6 (Fig. 2B).

Scanning electron microscopy provided a general description of initial infection events. Adhesion of some zoospores to the root could be observed as early as $1 \mathrm{~h}$ of incubation (Fig. 2C). From each zoospore cyst, a single germ tube emerged (Fig. 2D), which grew on the root surface for a short distance and then turned and invaded the root by growing between the anticlinal walls of the 
epidermal cells (Fig. 2E). After $10 \mathrm{~h}$, the zoospore walls collapsed (Fig. 2F) as the hyphae continued to colonize the root. No difference in these initial infection events was observed between Conrad and OX760-6.
Internal events during infection were observed with cleared and stained cross sections of infected roots. In both genotypes, $2 \mathrm{~h}$ after initial infection, many zoospores had germinated and germ tubes had grown toward the anticlinal walls of the epidermis (Fig.
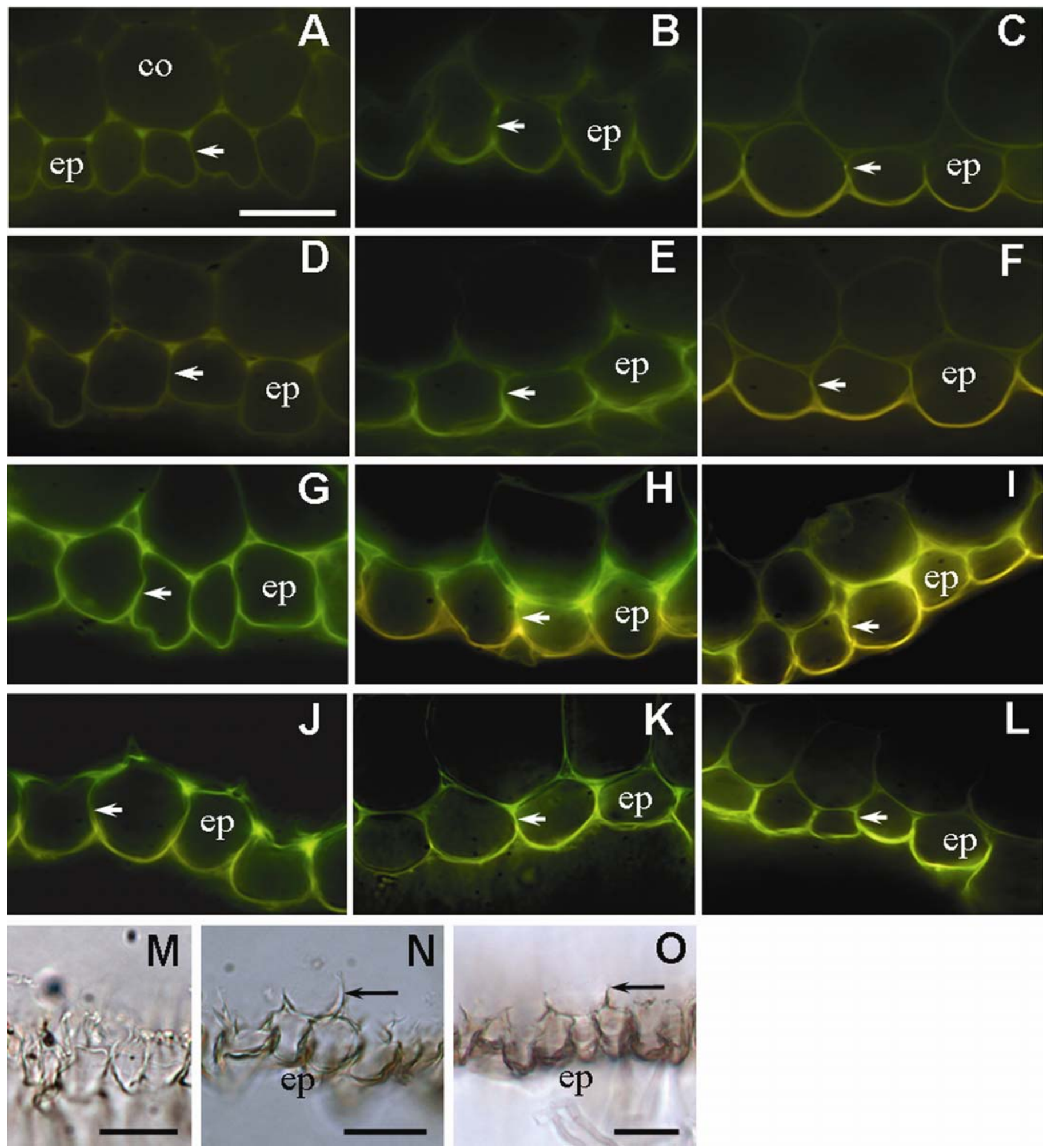

Fig. 1. Preformed suberin in the peripheral areas of soybean roots. Fresh, freehand, cross sections of primary roots of 10-day-old soybean seedlings. A to F, Sections mounted in water and viewed with blue light. Greenish yellow or yellowish orange autofluorescence indicates phenolics in all epidermal and some adjacent cortical cell walls. A to C, Autofluorescence of Conrad epidermis at A, $2 \mathrm{~mm}, \mathbf{B}, 10 \mathrm{~mm}$, and $\mathbf{C}, 50 \mathrm{~mm}$ from the root tip. D to F, Autofluorescence of OX760-6 epidermis at D, $2 \mathrm{~mm}, \mathbf{E}, 10 \mathrm{~mm}$, and $\mathbf{F}, 50 \mathrm{~mm}$ from the root tip. G to L, Cross sections stained with the lipophilic fluorochrome Fluorol yellow 088, G and $\mathbf{J}$ to $\mathbf{L}$, greenish yellow or $\mathbf{H}$ and $\mathbf{I}$, yellowish orange fluorescence indicates lipids in all walls of the epidermis and outer tangential and some radial walls of the adjacent cortical cells. G to I, Fluorescence of Conrad epidermis at $\mathbf{G}, 2 \mathrm{~mm}, \mathbf{H}, 10 \mathrm{~mm}$, and $\mathbf{I}, 50 \mathrm{~mm}$ from the root tip. J to $\mathbf{L}$, Fluorescence of OX760-6 epidermis at $\mathbf{J}, 2 \mathrm{~mm}, \mathbf{K}, 10 \mathrm{~mm}$, and $\mathbf{L}, 50 \mathrm{~mm}$ from the root tip. Arrowheads indicate radial cells walls of the epidermis. $\mathbf{M}$ to $\mathbf{O}$, Conrad cell walls remaining after acid digestion $\mathbf{M}, 2 \mathrm{~mm}, \mathbf{N}, 10 \mathrm{~mm}$, and $\mathbf{O}, 50 \mathrm{~mm}$ from the root tip. All outer tangential and radial walls of the epidermis are present, and the walls (arrows) of some adjacent cortical cells also resisted the acid in sections taken at 10 and $50 \mathrm{~mm}$ from the root tips. Bars $=50 \mu \mathrm{m}$, co $=$ cortical cells, ep $=\mathrm{epidermis}$. 
3A and B). However, the first penetration of hyphae through the epidermis, as well as intercellular extension in the cortex, was different for Conrad and OX760-6. Generally, $5 \mathrm{~h}$ after incubation, the extension of hyphae in Conrad was limited to the epidermis (Fig. 3C). In contrast, at this time penetration of hyphae into the mid-cortex through the epidermis was nearly complete (Fig. 4) in OX760-6 and haustoria were visible (Fig. 3D). In Conrad, it took approximately $8 \mathrm{~h}$ for hyphae to cross the epidermis and adjacent cortical layer (data not shown). After $10 \mathrm{~h}$ incubation, intercellular extension of hyphae in the mid-cortex of Conrad occurred and abundant haustoria were present (Fig. 3E), comparable to the $5 \mathrm{~h}$ time point in OX760-6.

Differences between penetration of hyphae through the endodermis of Conrad and OX760-6 were also evident. By $10 \mathrm{~h}$ after incubation with $P$. sojae zoospores, in OX760-6 hyphae had already crossed the endodermis and had grown into the stele (Fig. 3F). In these young root zones, the anticlinal walls of the endodermis of both genotypes had developed Casparian bands but not suberin lamellae (data not shown). The hyphae grew through the endodermal cells, breaching their outer and inner tangential walls. Hyphae in OX760-6 were much longer and more branched than those observed in Conrad. In Conrad after $24 \mathrm{~h}$ of incubation, many hyphal coils formed around the endodermis; only a few hyphae had penetrated the endodermis (Fig. $3 G)$. On the other hand in OX760-6, hyphae penetrating into the tracheary elements of xylem were very common (Fig. $3 \mathrm{H}$ ). In summary, the penetration and proliferation of hyphae through the epidermal and cortical layers and into the stele was quite slow in Conrad compared with OX760-6. This did not appear to be related to the ability of the pathogen to extract nutrients from its host, as $P$. sojae was able to establish normal biotrophic interactions with plant cells of both Conrad and OX760-6. Abundant haustoria and no evidence of cell death were observed during the initial colonization of roots of both genotypes.

The numbers of hyphal penetrations (percentage of total) through the epidermis and endodermis were estimated for Conrad and OX760-6 by dividing the number of sections with hyphae that penetrated the relevant layer by the total number of sections in which hyphae were observed at some position in the root for each infection time (Fig. 4). Even though the data collected could not be analyzed statistically, some interesting trends consistent with the histochemistry described above were observed. Thus, for both genotypes, no hyphae penetrated through the epidermis up to $2 \mathrm{~h}$ after initial inoculation. After $5 \mathrm{~h}$, about $80 \%$ of the observed hyphae penetrated the epidermis of OX760-6, whereas only $25 \%$ had done so in Conrad. Eight hours after inoculation, $80 \%$ of the observed hyphae had crossed the epidermis in Conrad roots, while virtually all hyphae had done so in OX760-6. At this time, no hyphae had crossed the endodermis and entered the stele in either genotype. At $10 \mathrm{~h}$ postinoculation, hyphae had still not breached the endodermis in Conrad, but $75 \%$ had done so in OX760-6. At $24 \mathrm{~h}$ after incubation of roots in the zoospore suspension, hyphae colonized the steles of both genotypes.

Time course of induced suberin deposition in soybean roots. To test whether inoculation with $P$. sojae induced the formation of new suberin in roots of soybean and, if so, where in the root this suberin was deposited, a longer term experiment was carried out. For inoculation, plants were grown in paper cups in which agar disks containing actively growing $P$. sojae had been placed at the bottom. Control cups contained sterile agar disks. In preliminary experiments, it was established that all primary soybean roots growing down into the rooting matrix encountered $P$. sojae hyphae after 6 days. (It was assumed that the hyphae did not grow toward the roots through the vermiculite.) No symptoms of root
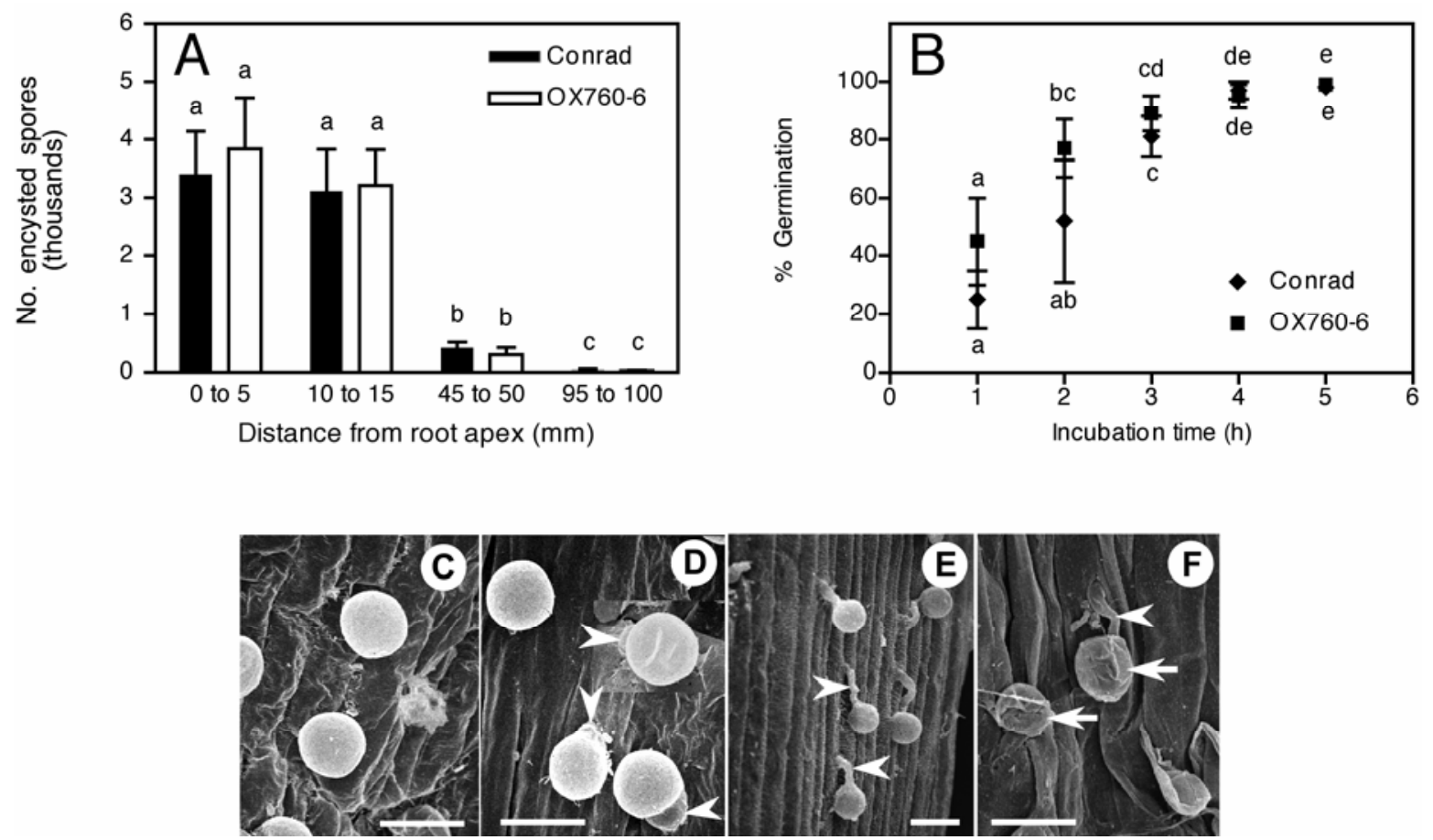

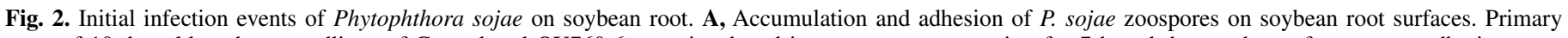

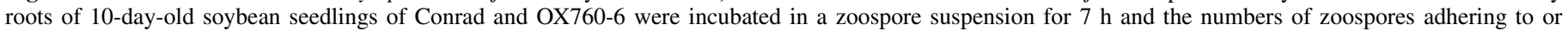

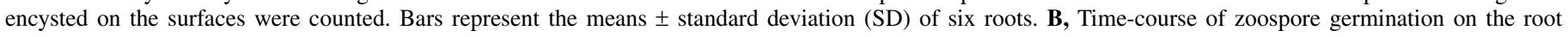

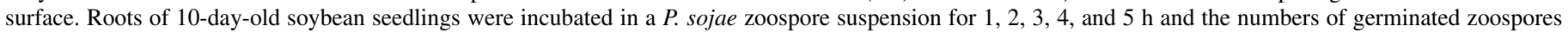

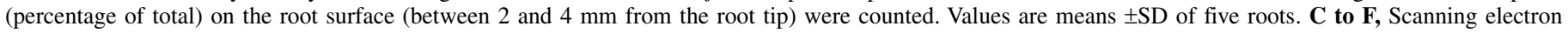

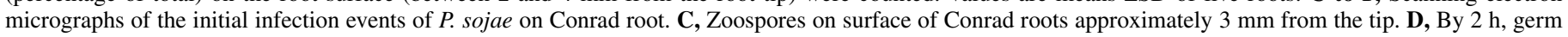

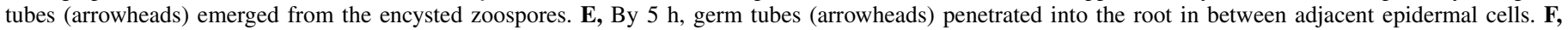

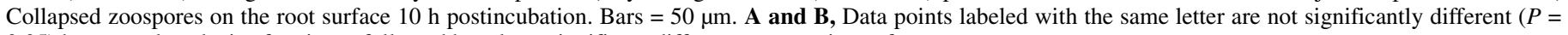
0.05 ) by general analysis of variance followed by a least significant difference comparison of means. 
rot or necrosis were observed in the noninoculated control roots throughout the following experiments. As expected, plants inoculated with the pathogen had reduced root length and clearly visible necrosis and root rot, but the latter was more severe in OX760-6 compared with Conrad. In OX760-6, necrosis extended the entire length of the root, but in Conrad it was confined to within $1 \mathrm{~cm}$ of the tip of the root portion remaining after
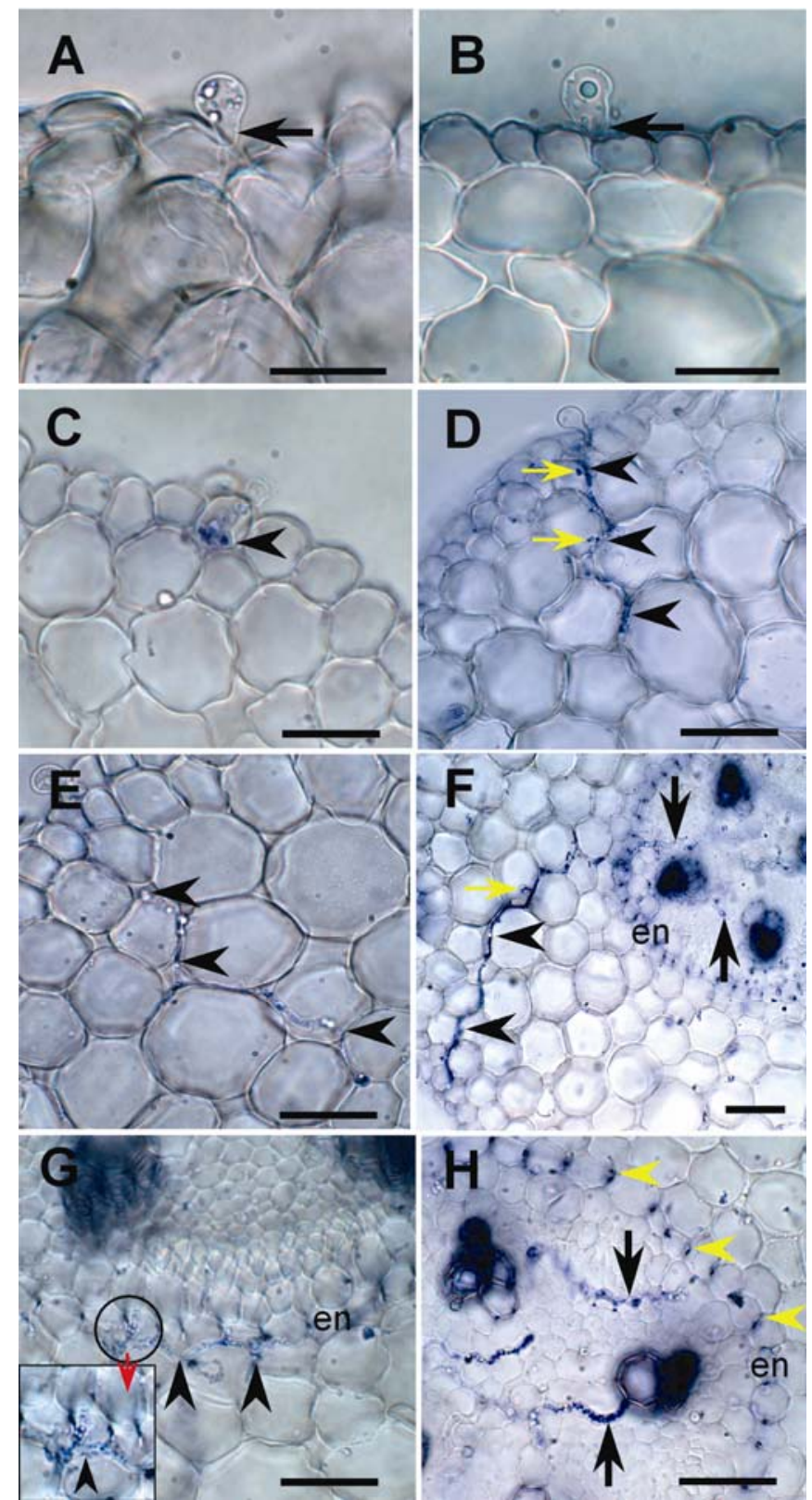

Fig. 3. Development of Phytophthora sojae in soybean roots. Freehand cross sections of roots of 10-day-old infected soybean seedlings taken $5 \mathrm{~mm}$ from the tip, cleared with $10 \%$ potassium hydroxide, stained with $2 \%$ Trypan blue, and viewed with white light. A and B, After $2 \mathrm{~h}$ incubation, zoospores had germinated on A, Conrad and B, OX760-6 roots. Arrows indicate germ tubes of zoospores. C, After $5 \mathrm{~h}$ incubation, extension of hyphae was limited to the epidermis in Conrad, whereas D, extension of hyphae into the mid-cortex through the epidermis was complete in OX760-6. Arrowheads show hyphae inside the roots, and yellow arrows indicate haustoria in the cortical cells. After $10 \mathrm{~h}$ incubation, E, hyphae had extended into the mid-cortex in Conrad, whereas F, they had crossed the endodermis in OX760-6. Arrowheads indicate hyphae inside the cortex and arrows show hyphae inside the stele. The yellow arrow indicates a haustorium in a cortical cell. G, At $24 \mathrm{~h}$ incubation, hyphal coils had formed in cells near the endodermis (arrowheads) in Conrad, while $\mathbf{H}$, hyphae entered into the xylem (arrows) in OX760-6. Yellow arrowheads show Casparian bands of the endodermis. G, Inset shows magnification of area denoted by circle. Bars $=30 \mu \mathrm{m}$. en $=$ endodermis. infection. In addition, no mortality was observed in Conrad, while several OX760-6 plants died during the 14-day incubation period (data not shown).

The amount of suberin in control and inoculated roots was monitored over an 8-day period after the initial contact between soybean and $P$. sojae (Fig. 5). There was a general trend for the suberin in control roots to increase over the sampling period (Fig. $5 \mathrm{~A}$ to $\mathrm{C}$ ). This was because additional cortical cells became suberized over time and older tissue made up an increasing proportion of the whole roots taken for analysis. Quantities of suberin components obtained from inoculated plants were a combination of preformed suberin ( $\mathrm{p}$-suberin) also present in noninoculated (control) plants and induced suberin (i-suberin) formed in response to the infection. The sum of these will be referred to as $\mathrm{p}+\mathrm{i}$-suberin. There were no qualitative (i.e., monomer composition) differences between $\mathrm{p}$ - and i-suberin (data not shown).

As expected, the amounts of all major suberin components (poly[aliphatics], poly[phenolics], and esterified phenolics), representing $\mathrm{p}+\mathrm{i}$-suberin, were greater in roots of both genotypes after pathogen infection compared with noninoculated controls (Fig. 5A to C). When the p-suberin values at each time point (46) were subtracted from the $\mathrm{p}+\mathrm{i}$-suberin values to give the amounts of i-suberin components accumulated in response to pathogen infection, differences in the timing of the deposition of suberin components between Conrad and OX760-6 roots became apparent. While roughly equal amounts of i-phenolics, i-esterified phenolics, and i-aliphatics were ultimately recovered from both genotypes by 8 days postinoculation, pathogen infection induced the deposition of all suberin components sooner in Conrad than in OX760-6 (Fig. 5D to F). However, there were no significant differences in the composition of $\mathrm{i}$-suberin monomers between the two genotypes (data not shown).

The most striking result from the time course study was the earlier induction of the aliphatic component of suberin in roots of Conrad plants. In these roots, the level of i-aliphatics increased from 0 to $7.50 \mu \mathrm{g} \mathrm{mg}^{-1}$ between 2 and 4 days postinoculation (Fig. 5D). In OX760-6, this induction did not begin until after 6 days. A similar accumulation pattern was observed for i-esterified phenolics. Induced levels increased very early, before day two, in Conrad roots compared with their induction in OX760-6 only after 4 days (Fig. 5E). This temporal difference in time of induc-

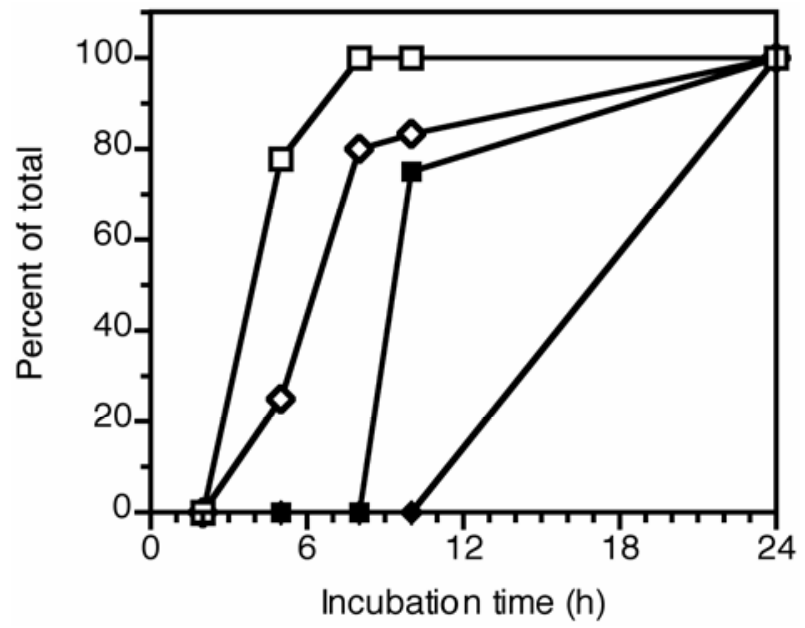

Fig. 4. Hyphal penetrations through the epidermis and endodermis. Roots of 10-day-old soybean seedlings were incubated in Phytophthora sojae zoospore suspensions, cross sectioned, cleared, and stained with Trypan blue. Numbers of hyphal penetrations (percent of total) through the epidermis and endodermis were counted for each incubation time. Open squares, OX760-6 epidermis; open diamonds, Conrad epidermis; closed squares, OX760-6 endodermis; and closed diamonds, Conrad endodermis. Number of replicates varied from three to nine. 
tion was not observed with i-poly(phenolics), which increased gradually from the outset in both genotypes but were only marginally higher in Conrad (Fig. 5F).

Location of induced suberin in internal tissues of roots. After infection, new suberin was deposited throughout the cortex of both Conrad and OX760-6. This was evident from the combined results of three tests: one for staining phenolics, one for staining aliphatics, and one for polymerization of these substances. Because there were no differences in staining reactions between Conrad and OX760-6 roots in control plants, only pictures of Conrad are shown. In control (noninoculated) plants of both genotypes, no phenolics were detected in the cortex or stele of the root (other than in the lignified xylem) by the HoepfnerVorsatz reaction (Fig. 6A). In contrast, at 8 days postinoculation, roots of both Conrad and OX760-6 had wall-associated phenolics throughout the cortex and the stele (Fig. 6B and C). Similarly, control (noninoculated) roots stained with Fluorol yellow 088 showed only faint yellow fluorescence in the cortex (along with significant autofluorescence of lignified tracheary element walls in the stele [Fig. 6D]). By contrast, stronger yellow fluorescence was observed in the walls of cortical cells of all infected primary roots, indicating deposition of lipids (Fig. 6E and F). Finally, a striking difference between control and infected roots was seen after bathing sections in concentrated sulfuric acid. That is, most of the cell walls in control sections were digested by the acid, leaving only the walls of the epidermis and parts of those of the vascular cylinder (Fig. 6G), whereas in sections from infected roots, all walls were retained (Fig. $6 \mathrm{H}$ and I). The combined results of these three tests indicate that infection of both Conrad and OX760-6 with $P$. sojae resulted in an extensive deposition of suberin in the walls of all cells of the cortex and stele. There were no evident spatial differences in the deposition of new suberin in infected roots of the two genotypes.

\section{DISCUSSION}

Our previous work established that preformed suberin (psuberin) is present in both the endodermis and epidermis (along with the adjacent cortex) of soybean roots $(9,46)$. Further, quantities of this suberin, especially the aliphatic part of the polymer, correlated positively with the level of the plants' partial resistance to root rot caused by $P$. sojae (46). However, $P$. sojae, like many other oomycetes, attacks roots by means of zoospores at the youngest region of the root $(5,8,12,14)$, and it was necessary to establish the pattern of p-suberin deposition at these early stages of root development. Our histochemical evidence indicates that for both genotypes, the outer tangential and radial walls of the epidermis, and even the middle lamellae between the radial walls, possessed suberin even in the youngest part of the root adjacent to the root cap. As the root aged, suberin was deposited in some walls of the adjacent cortex in both Conrad and OX760-6. With this new knowledge, it became possible to understand the role of suberin in the early stages of the soybean$P$. sojae interaction.

Infection of soybean roots by $\boldsymbol{P}$. sojae. Phytophthora zoospores are chemotactic to root exudates (57), and other studies have shown that zoospores rely on chemical and electrical cues to guide their homing responses $(5,51)$. In the case of soybean, $P$. sojae zoospores are attracted to isoflavones and perhaps other compounds secreted from the roots $(30,31,50)$. To reach the soil, these chemicals must pass through either the radial walls of the epidermis (if they are secreted into the walls of cortical cells) or the outer tangential walls of the epidermis (if they are secreted by the epidermis itself). Even though the cells in this root zone are suberized, they are known to be permeable to an apoplastic tracer of molecular weight (MW) 961 (9). Thus, it should be possible for isoflavones such as daidzein (MW 254) and genistein (MW 270) to be secreted by soybean roots.
Encysted zoospores started to germinate 1 to $2 \mathrm{~h}$ after exposure of the root to the zoospore-laden suspension. The resulting germ tubes typically grew on the root surface for a short distance, and then made an abrupt turn and invaded the root by extending through the middle lamellae of the radial walls of the epidermis, as shown earlier by Enkerli et al. (7). In both genotypes, the middle lamellae contain preformed suberin, based on the observation that epidermal cells failed to separate from each other during acid digestion (Fig. $1 \mathrm{M}$ to $\mathrm{O}$ ). Since a numerical comparison of attached encysted and subsequently germinated zoospores in Conrad versus OX760-6 showed no significant difference (Fig. $2 \mathrm{~A}$ and $\mathrm{B})$, the greater level of expression of partial resistance of Conrad to $P$. sojae is not a consequence of reduced attraction for the zoospores. This conclusion is in agreement with the findings of others $(1,13,29)$ who have studied the interaction of Phytoph-
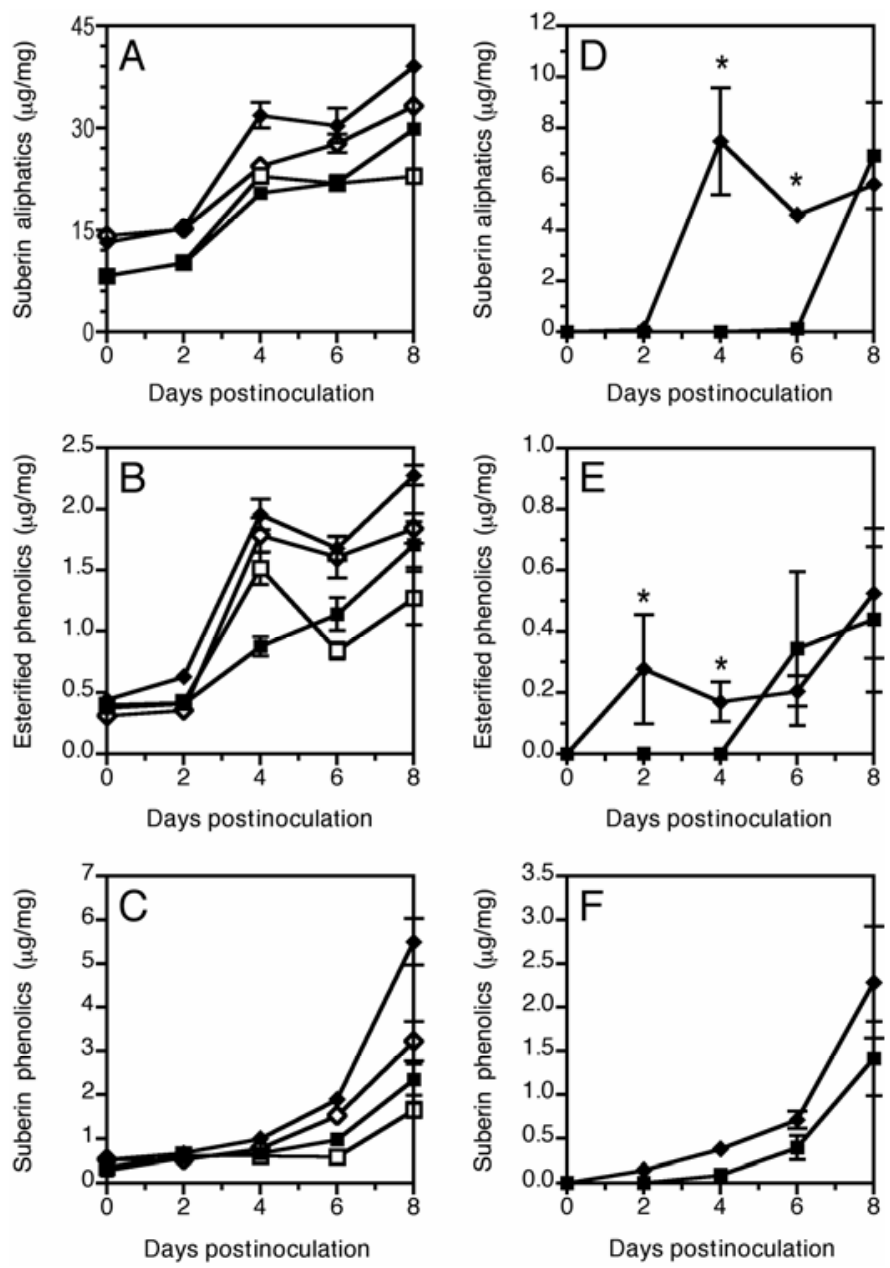

Fig. 5. Time course of whole root suberin in soybean genotypes inoculated with Phytophthora sojae. Parental genotypes Conrad and OX760-6 were grown in cups lined with agar disks containing $P$. sojae cultures and harvested over an 8-day period beginning 6 days after planting. After removal of necrotic portions, whole roots were subjected to analysis for $\mathbf{A}$, aliphatic suberin, B, esterified phenolics, and $\mathbf{C}$, suberin phenolics (NBO products). Diamonds, Conrad; squares, OX760-6; open symbols, preformed suberin components measured in control plants grown in the absence of $P$. sojae; and closed symbols, total (preformed + induced) suberin components measured in inoculated plants. Quantities of suberin and its components are expressed per unit dry weight of the root system. The amounts of $\mathbf{D}$, induced aliphatic suberin, E, induced esterified phenolics, and F, induced suberin phenolics (NBO products) were obtained by subtraction of preformed values from total values. Diamonds, Conrad; and squares, OX760-6. Data are from two replicate experiments, each with triplicate measurements $(N=6)$. Values at each time point are means \pm standard errors. Data points for Conrad that are labeled with an asterisk $(*)$ are significantly different $(P=0.05)$ from the corresponding data point for OX760-6, by general analysis of variance followed by a least significant difference comparison of means. 
thora spp. with plant roots. Further, laboratory assays for partial resistance (including our own) often employ mycelia rather than zoospore inoculation methods (33). The reliability of these mycelia-based assays and their correlation with field evaluations also suggests that zoospore attachment is not a determining factor in partial resistance.

A striking difference in the rate of pathogen invasion was noted when Conrad and OX760-6 were compared. In the latter, hyphal penetration and growth within the root was similar to that described by Enkerli et al. (7) for a compatible interaction between $P$. sojae and soybean. In contrast, in the present study, hyphae penetrated into the cortex more slowly in Conrad, resulting in an approximate 2 to $3 \mathrm{~h}$ delay of the infection (Fig. 3). This delay was not due to any difference in epidermal radial wall length (data not shown). Thus, in Conrad, the hyphae grew slowly through the middle lamella and, in some cases, hyphal growth appeared arrested at the interface between the epidermis and the outer tangential walls of the cortex where suberin precursors (i.e., phenolics and aliphatics) were present.

In highly susceptible interactions, $P$. sojae hyphae proliferate through the endodermis and are most abundant in the deep cell layers within the stele $(42,53)$. In the present study, the colonization of this region was clearly delayed in Conrad in comparison with OX760-6 (Figs. 3 and 4). The formation of hyphal coils in cortical cells adjacent to the endodermis and the absence of tangential wall modifications in Conrad (Fig. 3G and inset) strongly suggest an effective chemical defense at this point. The results of the present study show that hyphae entering the stele did so by growing through the outer and inner tangential walls of the endodermis, thus bypassing the radial walls with Casparian bands.
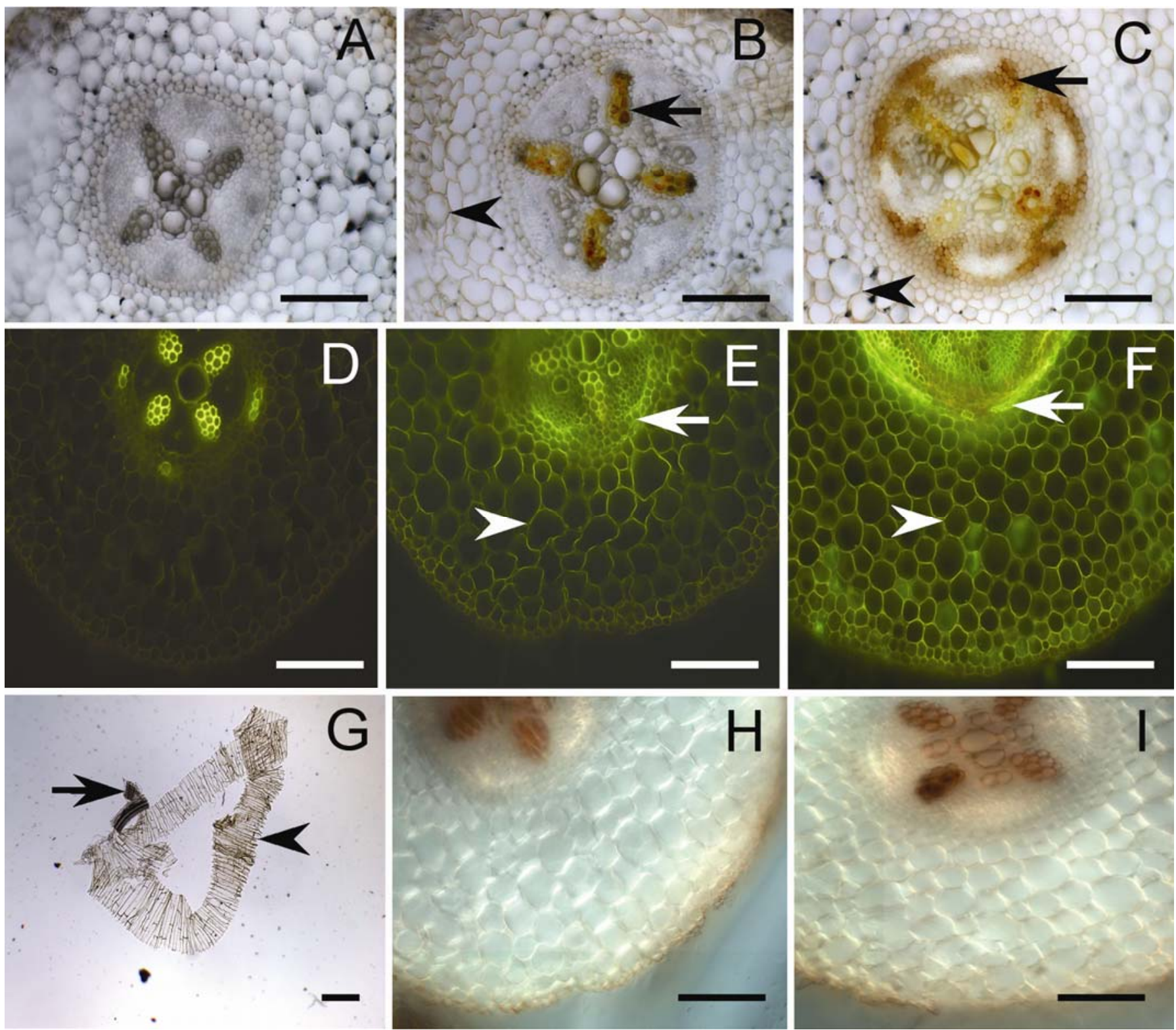

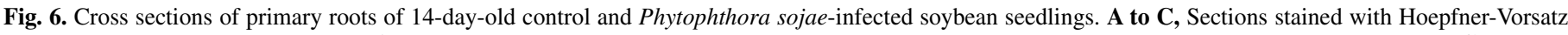

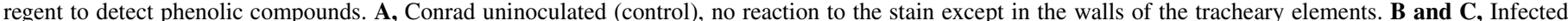

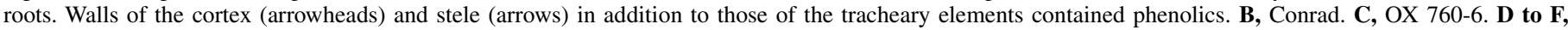

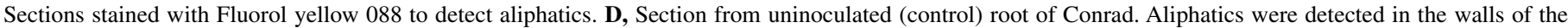

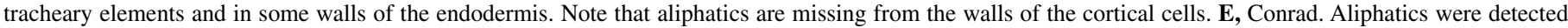

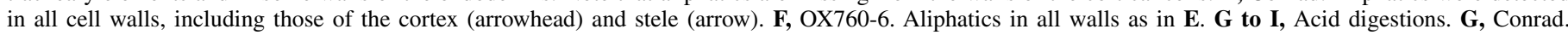

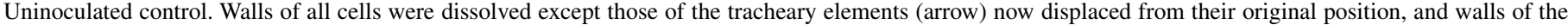

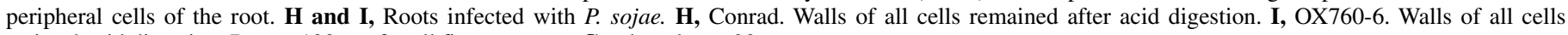
resisted acid digestion. Bars $=100 \mu \mathrm{m}$ for all figures except $\mathbf{G}$, where bar $=20 \mu \mathrm{m}$. 
Even in the youngest exposed epidermis, the outer tangential and radial walls contained suberin, so that such a facile growth across this cell layer was not possible.

The role of suberin in partial resistance to $P$. sojae. The time course of infection indicated delays in hyphal penetration through both the epidermis and endodermis of Conrad compared with OX760-6. In the case of the epidermis, we propose that the main difference in the speed of hyphal penetration is due to quantitative and qualitative differences in the suberin of the epidermal walls and middle lamellae. Consistent with this idea, epidermal cells of a young root region of Conrad have a twofold greater amount of p-suberin that is richer in aliphatics compared with OX760-6 $(9,46)$. The slower growth of the pathogen through the epidermis would provide additional time for the plant to mount its defenses. Early events are especially crucial in determining the outcome of any plant-pathogen interaction (16). In soybean, a plethora of defense responses are activated upon $P$. sojae infection, even in susceptible interactions $(32,35,52)$. The synthesis of isoflavonoid phytoalexins and other products that inhibit the growth of $P$. sojae are induced responses that require a reprogramming of gene expression patterns. Thus, any preformed chemical or structural elements that limit pathogen growth during the initial stages of ingress could be particularly effective in lessening the overall severity of infection by providing the plant more time to activate its additional defenses. Such a strategy would also explain the observed delay in hyphal growth through the endodermis and into the root stele of Conrad.

Is the observed delay in hyphal penetration through the epidermis related to p-suberin or i-suberin (or both)? Noninfected roots of both genotypes tested possessed i-suberin in the walls of their epidermis and endodermis. Subsequent to $P$. sojae infection, both genotypes responded with an extensive synthesis of new suberin. After 8 days, this material could be detected histochemically in walls of all the cells of the roots near the infection site in both Conrad and OX760-6 plants (Fig. 6). Of particular interest is the synthesis of the aliphatic component of the genotype, as previous work showed this to be the component that consistently correlated with increased partial resistance in this system $(45,46)$. However, this material developed after a lag time of at least 2 days (Fig. 5D), whereas $P$. sojae hyphae penetrated both the epidermis and endodermis of Conrad and OX760-6 roots by $24 \mathrm{~h}$. Although roots were inoculated in different ways in these two sets of experiments, it seems likely that i-suberin would not have been synthesized rapidly enough to influence an initial wave of infection. Perhaps the major function of this suberin is to act as a defense against subsequent attacks. If so, it is interesting to note that differences occur in the timing of i-suberin deposition in Conrad versus OX760-6. In the former, the aliphatics were synthesized earlier in the infection process, i.e., between 2 and 4 days after inoculation, whereas their synthesis began only after day 6 in OX760-6. That both Conrad and OX760-6 eventually showed equal amounts of $\mathrm{i}$-suberin possibly reflected the greater degree of pathogen growth within OX760-6. Nevertheless, the final outcome of partial resistance for this pathosystem, as crudely assessed by field mortality, does not correlate with amounts of total isuberin or with amounts of aliphatic i-suberin (45). The results of this and a previous paper (46) point to the importance of $\mathrm{p}$ suberin in influencing partial resistance in this case.

Comparison of partial resistance with race-specific resistance. It is clear that $P$. sojae is able to establish biotrophic associations with root cells of both Conrad and OX760-6, since abundant haustoria and no host cell death were noted for the early interactions with each of the cultivars. These results contrast with cytological descriptions of race-specific resistance conditioned by Rps genes. Specifically, host cell death during the initial stages of infection is more prevalent, and the number of pathogen haustoria observed is reduced in Rps-mediated resistant interactions $(7,53)$. These observations substantiate the view that partial resistance of soybean to $P$. sojae is usually different from race-specific resistance. Most Rps genes trigger a hypersensitive response that abruptly arrests the pathogen in the early stages of infection, although exceptions to this trend have been noted (27). For example, race-specific resistance in cv. Ripley, or that conditioned by the Rps 2 gene, each resemble partial resistance with regard to lesion length, oospore production, and infection frequency (27).

Although certain types of race-specific resistance may resemble partial resistance, it is also apparent that partial resistance in Conrad is not associated with a hypersensitive response. Nonetheless, the earlier induction of suberization in Conrad suggests that defenses are being triggered more rapidly or more robustly than in OX760-6. Greater levels of defense gene transcripts in $P$. sojaeinfected Conrad roots compared with susceptible types has also been noted in past studies (52). Taken together, these results imply a difference in surveillance or immune systems between the two types, as is the case with Rps-mediated immunity.

Another interpretation from the present study is that partial resistance in Conrad results from impedance of hyphal growth during ingress caused by greater levels of p-suberin in the roots (46). Constitutive, structural, and biochemical barriers provide a first line of defense to pathogens. Strengthening of root cell walls and middle lamellae by increased suberin deposition, or by other means, seems a plausible mechanism of resistance since $P$. sojae relies heavily on intercellular growth (7). In fact, a weakening of cells walls was cited as a possible explanation for the increased susceptibility that soybean plants displayed to $P$. sojae infection when grown in microgravity (39).

Which interpretation is correct? Does strong partial resistance result from differences in the host immune system and how this controls the rate of the defense response, or from differences in $\mathrm{p}$ suberin that is laid down prior to any pathogen challenge? Although we favor the latter hypothesis, it is possible that both interpretations may be correct. Mechanistically, strong partial resistance may differ depending on the genetic background. In the case of Conrad, since partial resistance is mediated by quantitative trait loci (QTL), there may be separate QTL that determine greater p-suberin, and that correspond to Rps-gene-like loci with a weak-effect, that nonetheless trigger defense reactions more rapidly. Further work, such as mapping QTL controlling root psuberin content and comparing these to known QTL that determine partial resistance, will help resolve this issue.

Development of cultivars with strong partial resistance to $\boldsymbol{P}$. sojae. The results of the present and a previous study (46) indicate the importance of epidermal p-suberin, especially its aliphatic component, in resisting $P$. sojae infection. Thus, a promising approach for generating soybean cultivars with increased partial resistance to $P$. sojae would be to augment their synthesis of root suberin. In fact, this approach may apply to many other pathosystems, since suberin is well known to resist the penetration of many organisms, and the epidermis of many roots contains this polymer (55). Possible counter-effects of increased suberin deposition in epidermal walls, such as reduced permeability to water and ions, need to be assessed to determine whether water or nutrient acquisition by the plant may be impaired. However, the relatively sparse suberin in the soybean epidermal walls compared with those of the Casparian bands of the endodermis (46) indicate that there should be considerable room for increasing suberin amounts in the epidermis without loss of root function.

\section{ACKNOWLEDGMENTS}

We thank D. Weber (University of Waterloo, Canada) for support with the scanning electron microscope and D. Qutob and A. Gaidauskas-Scott (Agriculture and Agri-Food Canada, London, Ontario, Canada) for assistance with seed collection. This research was funded by a Strategic Grant from the Natural Sciences and Engineering Research Council of Canada. 


\section{LITERATURE CITED}

1. Beagle-Ristaino, J. E., and Rissler, J. F. 1983. Histopathology of susceptible and resistant soybean roots inoculated with zoospores of Phytophthora megasperma f. sp. glycinea. Phytopathology 73:590-595.

2. Brundrett, M. C., Kendrick, B., and Peterson, C. A. 1991. Efficient lipid staining in plant materials with Sudan red 7B or Fluorol yellow 088 in polyethylene glycol-glycerol. Biotech. Histochem. 66:111-116.

3. Burnham, K. D., Dorrance, A. E., Van Toai, T. T., and St. Martin, S. K. 2003. Quantitative trait loci for partial resistance to Phytophthora sojae in soybean. Crop Sci. 43:1610-1617.

4. Buzzell, R. I., and Anderson, T. R. 1982. Plant loss response of soybean cultivars to Phytophthora megasperma f. sp. glycinea under field conditions. Plant Dis. 66:1146-1148.

5. Deacon, J. W., and Donaldson, S. P. 1993. Molecular recognition in the homing responses of zoosporic fungi, with special reference to Pythium and Phytophthora. Mycological Res. 97:1153-1171.

6. Dorrance, A. E., McClure, S. A., and St. Martin, S. K. 2003. Effect of partial resistance on Phytophthora stem rot incidence and yield of soybean in Ohio. Plant Dis. 87:308-312.

7. Enkerli, K., Hahn, M. G., and Mims, C. W. 1997. Ultrastructure of compatible and incompatible interactions of soybean roots infected with the plant pathogenic oomycete Phytophthora sojae. Can. J. Bot. 75:14931508.

8. Erwin, D. C., and Ribeiro, O. K. 1996. Phytophthora Diseases Worldwide. The American Phytopathological Society, St. Paul, MN.

9. Fang, X. 2006. Chemical composition of soybean root epidermal cell walls. M.Sc. Thesis, University of Waterloo, Canada.

10. Gijzen, M. 2004. Oomycete-plant interactions: Current issues. Pages 843845 in: Encyclopedia of Plant and Crop Science. R. M. Goodman, ed. University of Wisconsin, Madison, WI.

11. Hardham, A. R. 2007. Cell biology of plant-oomycete interactions. Cell. Microbiol. 9:31-39.

12. Hickman, C. J. 1970. Biology of Phytophthora zoospores. Plant Phytopathol. 60:1128-1135.

13. Hickman, C. J., and Ho, H. H. 1966. Behavior of zoospores in plantpathogenic Phycomycetes. Annu. Rev. Phytopathol. 4:195-220.

14. Ho, H. H., and Hickman, C. J. 1967. Factors governing zoospore responses of Phytophthora megasperma var. sojae to plant roots. Can. J. Bot. 45:1983-1994.

15. Johansen, D. A. 1940. Plant Microtechnique. McGraw-Hill, New York.

16. Jones, J. D., and Dangl, J. L. 2006. The plant immune system. Nature 444:323-329.

17. Kaitany, R. C., Hart, L. P., and Safir, G. 2001. Virulence composition of Phytophthora sojae in Michigan. Plant Dis. 85:1103-1106.

18. Kamoun, S. 2000. Phytophthora. Pages 1-32 in: Fungal Pathology. J. Kronstad, ed. Kluwer Academic Publishers, Dordrecht, The Netherlands.

19. Kaufmann, M. J., and Gerdemann, J. W. 1958. Root and stem rot of soybean caused by Phytophthora sojae n. sp. Phytopathology 48:201-208.

20. Kolattukudy, P. E., and Espelie, K. E. 1989. Chemistry, biochemistry and functions of suberin-associated waxes. Pages 235-287 in: Natural Products of Woody Plants. J. W. Rowe, ed. Springer-Verlag, New York.

21. Kormanik, P. P., and McGraw, A.-C. 1982. Quantification of vesiculararbuscular mycorrhizae in plant roots. Pages 37-45 in: Methods and Principles of Mycorrhizal Research. N. C. Schenck, ed. The American Phytopathological Society, St. Paul, MN.

22. Ling-Lee, M., Chilvers, G. A., and Ashford, A. E. 1977. A histochemical study of phenolic materials in mycorrhizal and uninfected roots of Eucalyptus fastigata Deane and Maiden. New Phytol. 78:313-328.

23. Loomis, W. E., and Schull, C. A. 1937. Page 63 in: Methods in Plant Physiology. A Laboratory Manual and Research Handbook. McGraw-Hill, New York.

24. Lulai, E. C. 2005. Non-wound-induced suberization of tuber parenchyma cells: A physiological response to the wilt disease pathogen Verticillium dahliae. Am. J. Potato Res. 82:433-440.

25. Lulai, E. C., and Corsini, D. L. 1998. Differential deposition of suberin phenolic and aliphatic domains and their roles in resistance to infection during potato tuber (Solanum tuberosum L.) wound healing. Physiol. Mol. Plant Biol. 53:209-222.

26. Lulai, E. C., Weiland, J. J., Suttle, J. C., Sabba, R. P., and Bussan, A. J. 2006. Pink eye is an unusual periderm disorder characterized by aberrant suberization: A cytological analysis. Am. J. Potato Res. 83:409-421.

27. Mideros, S., Nita, M., and Dorrance, A. E. 2007. Characterization of components of partial resistance, Rps2, and root resistance to Phytophthora sojae in soybean. Phytopathology 97:665-662.

28. Meyer, K., Shirley, A. M., Cusumano, J. C., Bell-Lelong, D. A., and Chapple, C. 1998. Lignin monomer composition is determined by the expression of a cytochrome P450-dependent monooxygenase in Arabidopsis. Proc. Natl. Acad. Sci. USA 95:6619-6623.

29. Miller, S. A., and Maxwell, D. P. 1984. Light microscope observations of susceptible, host resistant, and nonhost resistant interactions of alfalfa with Phytophthora megasperma. Can. J. Bot. 62:109-116.

30. Morris, P. F., Bone, E., and Tyler, B. M. 1998. Chemotropic and contact responses of Phytophthora sojae hyphae to soybean isoflavonoids and artificial substrates. Plant Physiol. 117:1171-1178.

31. Morris, P. F., and Ward, E. W. B. 1992. Chemoattraction of zoospores of the soybean pathogen Phytophthora sojae by isoflavones. Physiol. Mol. Plant Pathol. 40:17-22.

32. Moy, P., Qutob, D., Chapman, B. P., Atkinson, I., and Gijzen, M. 2004. Patterns of gene expression upon infection of soybean plants by Phytophthora sojae. Mol. Plant-Microbe Interact. 17:1051-1062.

33. Olah, A. F., and Schmitthenner, A. F. 1985. A growth chamber test for measuring Phytophthora root rot tolerance in soybean seedlings. Phytopathology $74: 546-548$.

34. Peterson, C. A., Peterson, R. L., and Robards, A. W. 1978. A correlated histochemical and ultrastructural study of the epidermis and hypodermis of onion roots. Protoplasma 96:1-21.

35. Qutob, D., Hraber, P. T., Sobral, B. W., and Gijzen, M. 2000. Comparative analysis of expressed sequences in Phytophthora sojae. Plant Physiol. 123:243-254.

36. Reiderer, M., and Schönherr, J. 1986. Quantitative gas chromatographic analysis of methyl esters of hydroxy fatty acids derived from plant cutin. J. Chromatog. 360:151-161.

37. Reeve, R. 1951. Histochemical tests for polyphenols in plant tissues. Stain Technol. 26:91.

38. Robb, J., Leem, S. W., Mohan, R., and Kolattukudy, P. E. 1991. Chemical characterization of stress-induced vascular coating in tomato. Plant Physiol. 97:528-536.

39. Ryba-White, M., Nedukha, O., Hilaire, E., Guikema, J. A., Kordyum, E., and Leach, J. E. 2001. Growth in microgravity increases susceptibility of soybean to a fungal pathogen. Plant Cell Physiol. 42:657-664.

40. Schmitthenner, A. F. 1985. Problems and progress in control of Phytophthora root rot of soybean. Plant Dis. 69:362-368.

41. Schmitthenner, A. F., and Van Doren, D. M. 1985. Integrated control of root rot of soybean caused by Phytophthora megasperma f. sp. glycinea. Pages 263-266 in: Ecology and Management of Soilborne Plant Pathogens. C. A. Parker, A. D. Rovira, K. J. Morre, and P. T. W. Wong, eds. American Phytopathological Society, St. Paul, MN.

42. Stössel, P., Lazarovits, G., and Ward, E. W. B. 1980. Penetration and growth of compatible and incompatible races of Phytophthora megasperma var. sojae in soybean hyopcotyl tissues differing in age. Can. J. Bot. 58:2594-2607.

43. Stössel, P., Lazarovits, G., and Ward, E. W. B. 1981. Differences in the mode of penetration of soybean hyopcotyl by two races of Phytophthora megasperma var. sojae. Can. J. Bot. 59:1117-1119.

44. St. Martin, S. K., Scott, D. R., Schmitthenner, A. F., and McBlain, B. A. 1991. Relationship between tolerance to Phytophthora rot and soybean yield. Plant Breed. 113:331-334.

45. Thomas, R. H. 2006. Suberization in soybean roots and its role in disease tolerance. Ph.D. Thesis. The University of Western Ontario, Canada.

46. Thomas, R. H., Fang, X., Ranathunge, K., Anderson, T. R., Peterson, C. A., and Bernards, M. A. 2007. Soybean root suberin: Anatomical distribution, chemical composition and relation to partial resistance to Phytophthora sojae. Plant Physiol. 144:299-311.

47. Tooley, P. W., and Grau, C. R. 1984. Field characterization of ratereducing resistance to Phytophthora megasperma f. sp. glycinea in soybean. Phytopathology 74:1201-1208.

48. Tyler, B. M. 2002. Molecular basis of recognition between Phytophthora pathogens and their host. Ann. Rev. Phytopathol. 40:137-167.

49. Tyler, B. M. 2007. Phytophthora sojae: Root rot pathogen of soybean and model oomycete. Mol. Plant Pathol. 8:1-8.

50. Tyler, B. M., Wu, M., Wang, J., Cheung, W., and Morris, P. F. 1996. Chemotactic preferences and strain variation in the response of Phytophthora sojae zoospores to host isoflavones. Appl. Environ. Microbiol. 62:2811-2817.

51. Van West, P., Morris, B. M., Reid, B., Appiah, A. A., Osborne, M. C., Campbell, T. A., and Shepherd, S. J. 2002. Oomycete plant pathogens use electric fields to target roots. Mol. Plant-Microbe Interact. 15:790-798.

52. Vega-Sánchez, M. E., Redinbaugh, M. G., Costanzo, S., and Dorrence, A. E. 2005. Spatial and temporal expression analysis of defence-related genes in soybean cultivars with different levels of partial resistance to Phytophthora sojae. Physiol. Mol. Plant Pathol. 66:175-182.

53. Ward, E. W. B., Cahill, D. M., and Bhattacharyya, M. K. 1989. Early cytological differences between compatible and incompatible interactions of soybeans with Phytophthora megasperma f. sp. glycinea. Physiol. Mol. Plant Pathol. 34:267-283.

54. Welc, M. 2004. Mikoryza arbuskularna topoli (Populus sp.): Porównanie kolonizacji mikoryzowej wybranych gatunków i odmian hodowlanych topoli rosncych w glebie kontrolnej i zanieczyszczonej pestycydami. [Influence of soil conditions on the growth and development of selected 
poplar hybrids and their mycorrhizal associations.] M.Sc. Thesis, Akademia Bydgoska im. Kazimierza Wielkiego w Bydgoszczy, Poland.

55. Wilson, C. A., and Peterson, C. A. 1983. Chemical composition of the epidermal, hypodermal, endodermal and intervening cortical cell walls of various plant roots. Ann. Bot. 51:759-769.
56. Yang, W.-L., and Bernards, M. A. 2006. Wound induced metabolism in potato (Solanum tuberosum) tubers: Biosynthesis of aliphatic domain monomers. Plant Signal. Behav. 1:59-66.

57. Zentmyer, G. A. 1961. Chemotaxis of zoospores for root exudates. Science 133:1595-1596. 